\title{
Microwave Enabled One-Pot, One-Step Fabrication and Nitrogen Doping of Holey Graphene Oxide for Catalytic Applications
}

\author{
Mehulkumar Patel, Wenchun Feng, Keerthi Savaram, M. Reza Khoshi, \\ Ruiming Huang, Jing Sun, Emann Rabie, Carol Flach, Richard Mendelsohn, \\ Eric Garfunkel, and Huixin He*
}

\begin{abstract}
The unique properties of a holey graphene sheet, referred to as a graphene sheet with nanoholes in its basal plane, lead to wide range of applications that cannot be achieved by its nonporous counterpart. However, the large-scale solution-based production requires graphene oxide $(G O)$ or reduced $G O(r G O)$ as the starting materials, which take hours to days for fabrication. Here, an unexpected discovery that $G O$ with or without holes can be controllably, directly, and rapidly (tens of seconds) fabricated from graphite powder via a one-step-one-pot microwave assisted reaction with a production yield of $120 \mathrm{wt} \%$ of graphite is reported. Furthermore, a fast and low temperature approach is developed for simultaneous nitrogen $(N)$ doping and reduction of $G O$ sheets. The $N$-doped holey $r G O$ sheets demonstrate remarkable electrocatalytic capabilities for the electrochemical oxygen reduction reaction. The existence of the nanoholes provides a "short cut" for efficient mass transport and dramatically increases edges and surface area, therefore, creates more catalytic centers. The capability of rapid fabrication and $\mathrm{N}$-doping as well as reduction of holey $G O$ can lead to development of an efficient catalyst that can replace previous coin metals for energy generation and storage, such as fuel cells and metal-air batteries.
\end{abstract}

M. Patel, K. Savaram, M. Reza Khoshi, R. Huang, J. Sun, E. Rabie, Dr. C. Flach, Prof. R. Mendelsohn, Prof. H. He Chemistry Department

Rutgers University

73 Warren Street, Newark, NJ 07102, USA

E-mail: huixinhe@rutgers.edu

Dr. W. Feng

Department of Chemical Engineering

University of Michigan

2800 Plymouth Road, Ann Arbor, MI 48109, USA

Prof. E. Garfunkel

Department of Chemistry and Chemical Biology

Rutgers University

610 Taylor Rd, Piscataway, NJ 08854, USA

DOI: $10.1002 /$ smll.201403402

\section{Introduction}

The ever-increasing global depletion of fossil resources and their environmental impacts stimulate intense research activities in the development of alternative green and sustainable energy resources. Fuel cells and metal-air batteries are the most attractive clean and high-efficiency devices for power generation and energy storage. ${ }^{[1-3]}$ However, their large-scale practical application will be difficult to realize if the expensive platinum-based electrocatalysts for oxygen reduction reaction (ORR) cannot be replaced by efficient, stable, low-cost, and sustainable catalysts in their electrodes. Recent efforts in reducing/replacing expensive platinumbased electrodes have led to the development of new ORR 
small

www.MaterialsViews.com

electrocatalysts. ${ }^{[4-9]}$ Among them, graphene, especially the heteroatom doped graphene shows outstanding potentials as metal free catalysts. However, practical application of the graphene based metal free catalyst is hampered due to its remarkable impermeability. ${ }^{[10]}$ Hence, the reactants and products cannot access/leave the inner catalytic sites easily, which results in unsatisfactory performance and non-efficient mass transport. In contrast, holey graphene, referred to graphene sheets with nanoholes in its basal plane, not only provides "short cut" for efficient mass transport, but also possess significantly more catalytic centers due to the increased edges associated with the existence of holes. Several approaches have been reported for the production of holey graphene sheets. Bottom-up approaches based on chemical vapor deposition method, ${ }^{[11-13]}$ and top-down approaches via photo, ${ }^{[14]}$ electron, ${ }^{[15]}$ or plasma ${ }^{[11]}$ etching utilize various templates, which provide good control over the sizes and shapes of the holes/pores. However, all these strategies suffer from difficulties in scaling up for large quantity production and high cost. On the other hand, chemical etching based processes, such as $\mathrm{KOH}$ etching, ${ }^{[16]} \mathrm{H}_{3} \mathrm{PO}_{4}$ activation, ${ }^{[17]} \mathrm{HNO}_{3}$ oxidation, ${ }^{[18,19]}$ hot steam etching, ${ }^{[20]}$ and oxidative etching with catalytic nanoparticle such as $\mathrm{Fe}_{2} \mathrm{O}_{3},{ }^{[21]} \mathrm{Ag},{ }^{[22]}$ or other metal oxide nanoparticles ${ }^{[23]}$ have advantages for large scale and cost effective synthesis. However, these chemical etching based approaches require graphene oxide $(\mathrm{GO})$ or reduced graphene oxide (rGO) as a starting material, which takes hours to days for their fabrication, depending on the oxidation method applied. There is no approach that has been reported yet to rapidly fabricate holey graphene directly from graphite particles. Herein, we report our unexpected discovery that by replacing traditional heating with microwave heating, holey graphene oxide (HGO) sheets are directly and rapidly (40 s) fabricated from graphite particles via a one-step-onepot reaction. Furthermore, by slightly shortening the microwave heating time, graphene oxide (GO) sheets without holes can be rapidly fabricated. This approach has the similar chemical recipe as the widely used Hummers method, but dramatically shortened the reaction time from days to tens of seconds with high production yield (120 wt \% of graphite).

Heteroatom (N, P, B, and S) doping in graphene can effectively tailor its electronic properties and thus have a great impact on its wide range of applications in electronics, energy storage, and metal free catalysts applications. ${ }^{\text {[24-35] }}$ There are quite a few methods available for nitrogen $(\mathrm{N})$ doping. ${ }^{[32,36-43]}$ However, all of these approaches require long time and/or high annealing temperature with various $\mathrm{N}$ containing molecules. Again, by taking advantage of the unique heating mechanism of microwave, we developed a fast and low temperature approach to simultaneously reduce and dope graphene oxide sheets with nitrogen. The N-doping type can be controlled simply by changing the microwave time. With 10 min of microwave irradiation, pyridinic $\mathrm{N}$ and pyrrolic $\mathrm{N}$ reach the highest percentage in holey graphene sheets, which show the best catalytic activity toward electrochemical ORR. These N-doped holey rGO(N-HrGO-10) sheets not only offer the lower overpotential and peak potential but also provide more than 4 times higher kinetic current density than nonporous $\mathrm{N}$-doped $\mathrm{rGO}(\mathrm{N}-\mathrm{rGO}-10)$. It is likely due to the existence of nanoholes, which provides "short cut" for efficient mass transport and also creates more catalytic centers due to the increased surface area and edges associated with the nanoholes in the N-HrGO-10. For the first time, we experimentally determined the effective diffusion coefficient constant of $\mathrm{O}_{2}$ for the N-HrGO-10, which is indeed significantly higher than that of the N-rGO-10. Even though the onset potential is slightly higher than the $\mathrm{Pt} / \mathrm{C}(0.09 \mathrm{~V})$, the $\mathrm{N}-\mathrm{HrGO}-10$ shows much higher catalytic current, better stability, and durability against methanol poisoning. The capability to rapid fabrication and $\mathrm{N}$-doping of $\mathrm{HGO}$ can lead us to develop efficient catalysts which can replace previous coin metals for energy generation and storage, such as fuel cells and metal-air batteries.

\section{Results and Discussion}

Recently, we developed a fast, scalable, and low-energy approach to directly produce graphene nanosheets (GNs) from graphite powder. ${ }^{[4]}$ These graphene nanosheets are highly uniform in size and largely retain their intrinsic graphitic structures without any post-reduction treatment. The key is to exclude $\mathrm{KMnO}_{4}$ (as used in Hummers or Modified Hummers methods) and exploit pure nitronium ion oxidation and the unique thermal and kinetic effects induced by microwave heating. Due to the unique effects of microwave heating, it is very likely that consumption/etching of defective carbons (already oxidized carbon or $s p^{3}$ carbon) was selectively enhanced more than that of the continuing oxidation of intact graphene domains (generation of more oxygen containing groups). As a result, the graphene sheets rapidly breakdown to small pieces with the intrinsic structures of graphene largely intact. In this work, we found that by including $\mathrm{KMnO}_{4}$ in the reaction system, and by adjusting microwave irradiation time and amount of $\mathrm{KMnO}_{4}$, the etching/consumption of the generated defective carbons can be controlled, so that graphene oxide sheets with controlled hole structures can be directly fabricated from graphite powder in one step.

In a typical experiment, the mixture of graphite powder, acids (concentrated $\mathrm{H}_{2} \mathrm{SO}_{4}: \mathrm{HNO}_{3}, 4: 1$ ) and $\mathrm{KMnO}_{4}$ (500 wt \% of graphite) was subjected to microwave irradiation at $300 \mathrm{~W}$ for different times $(30 \mathrm{~s}$ for $\mathrm{GO}$ or $40 \mathrm{~s}$ for $\mathrm{HGO}$ ). The resulting products, after cleaning, are easy to disperse in water by simple bath sonication. Their dispersions in water have brown color (inset of Figure 1c and Figure S1b, Supporting Information), independent of microwave irradiation time. They all exhibit the typical $\approx 230 \mathrm{~nm}$ peak in UV-vis spectrum (Figure 1c and Figure S1b, Supporting Information, respectively) due to $\pi \rightarrow \pi^{*}$ transition of $\mathrm{C}=\mathrm{C}$ and shoulder around $300 \mathrm{~nm}$ due to the $n \rightarrow \pi^{*}$ transition of carbonyl functional group. X-ray photoelectron spectroscopy (XPS) measurements were performed to carefully study their oxidation level and chemical functionalities. Interestingly, high resolution C1s (Figure 2a and Figure S2a, Supporting Information) and O1s peak (Figure S3b, Supporting Information) analysis of $\mathrm{GO}$ and $\mathrm{HGO}$ shows that the $\mathrm{C}: \mathrm{O}$ atomic ratio is $\approx 2.38$, similar in both GO (Table $\mathrm{S} 1$, 

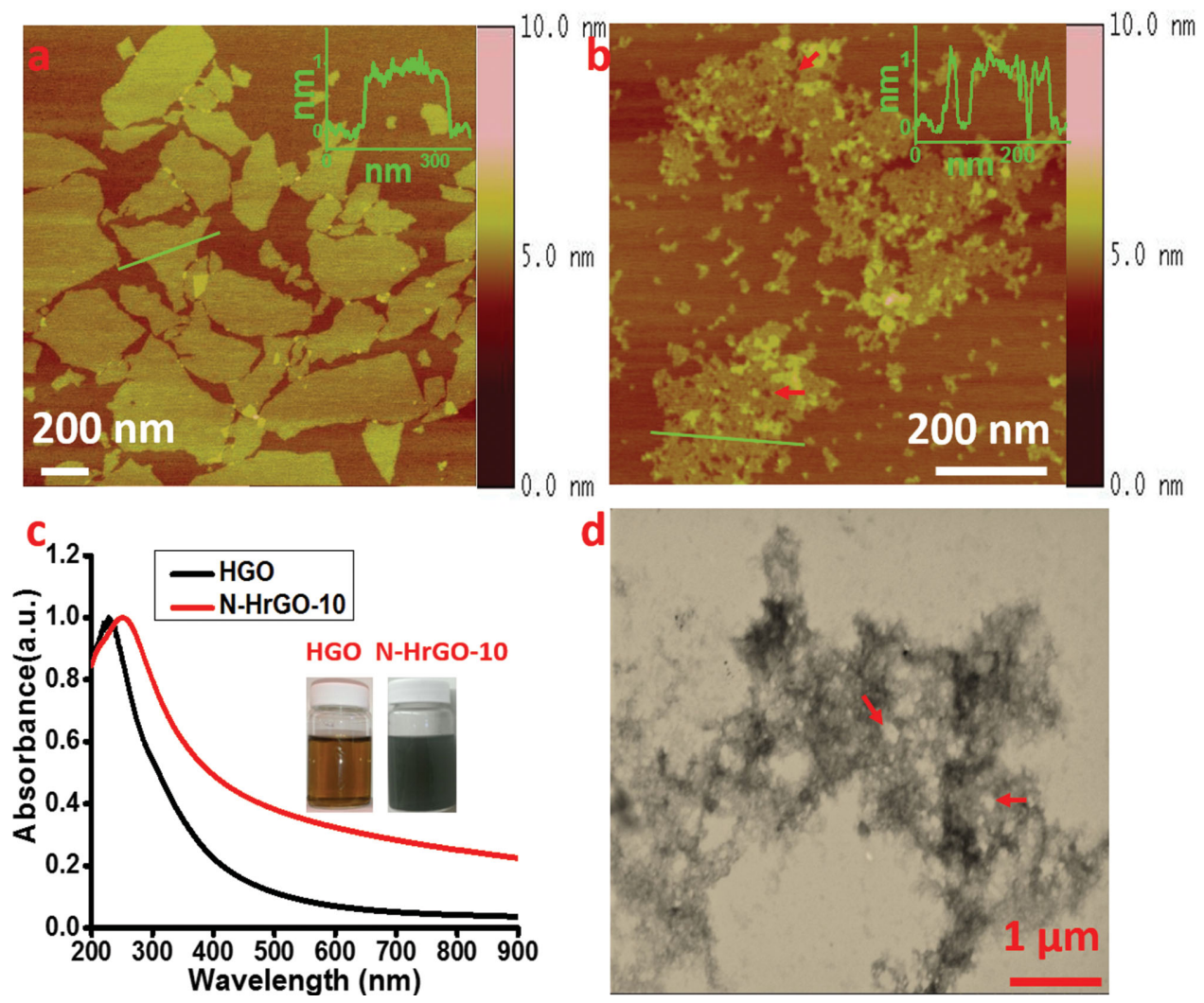

Figure 1. a) AFM of GO sheets obtained via $30 \mathrm{~s}$ of microwave irradiation. b) AFM and d) STEM images of HGO sheets obtained via $40 \mathrm{~s}$ of microwave irradiation. c) UV-vis-NIR spectra of HGO and N-HrGO-10 in water. Inset in (c) is a digital picture of an aqueous dispersion of $\mathrm{HGO}$ (left), $\mathrm{N}-\mathrm{HrGO}-10$ (right) shows different color, indicating their different oxidation states. The red arrows in (b,d) show hole on HGO sheet.
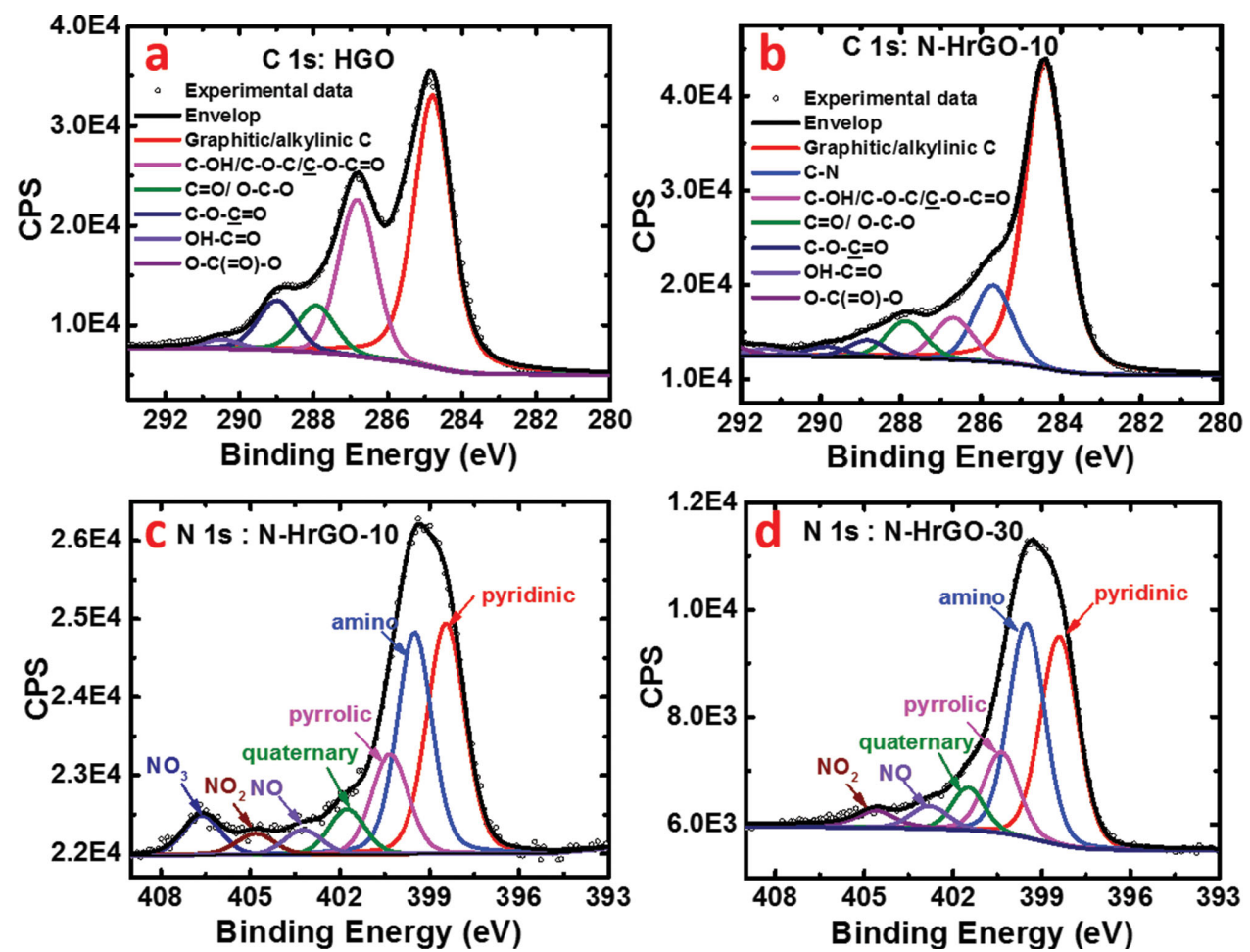

Figure 2. XPS high resolution C1s peak analysis of $\mathrm{HGO}$ (a) and N-HrGO-10 (b). XPS high resolution N1s peak analysis of N-HrGO-10 (c) and $\mathrm{N}-\mathrm{HrGO}-30$ (d), where 10 and 30 denotes microwave treatment time (in minutes) of $\mathrm{HGO}$ with $\mathrm{NH}_{4} \mathrm{OH}$ at $120^{\circ} \mathrm{C}$. 
small

www.MaterialsViews.com

Supporting Information), which indicates that both GOs have similar extent of oxidation in spite of different microwave time.

However, we found that microwave irradiation time dramatically changed their geometric structures. For instance, $30 \mathrm{~s}$ of microwave irradiation resulted in GO sheets with nanoholes seldom being observed in the basal planes. The atomic force microscopy (AFM) and scanning transmission electron microscopy (STEM) (Figure 1a and Figure S1a, Supporting Information) images show that most of the sheets are single layered and nonporous. Similar to the GO sheets produced via modified Hummer's method, these sheets have straight edges, indicating the dominant linear unzipping effect of $\mathrm{KMnO}_{4}{ }^{[45]}$ While, with a $40 \mathrm{~s}$ of microwave irradiation, the lateral size of the GO sheets obtained is slightly decreased and their edges are not straight anymore from their AFM and STEM images (Figure 1b, d, Figure S4, Supporting Information). More importantly, holes (from several nanometers to a few hundred nanometers) are randomly distributed across the entire sheets, demonstrating that holey GO (HGO) is directly fabricated from graphite powder via a fast, one-stepone-pot reaction. Further, the surface area of GO and HGO, after vacuum dry, was measured by methylene blue (MB) dye adsoprtion approach (Table S2, Supporting Information). [46] We found that the surface area of HGO $\left(1424.16 \mathrm{~m}^{2} \mathrm{~g}^{-1}\right)$ is $\approx 1.5$ times higher than that of GO $\left(947.55 \mathrm{~m}^{2} \mathrm{~g}^{-1}\right)$, possibly due to the existence of the holes in HGO. To our knowledge, this is the first report that solution phase GO with controlled hole structures can be rapidly fabricated directly from graphite powder (Table S3, Supporting Information).

Beside the difference in their edge morphology and hole structure of the GO and HGO, the color of the filtrate (waste), collected during cleaning via filtration, is also different. While the one obtained from GO cleaning is colorless, the one from HGO cleaning is light yellow (Figure S6c-II, Supporting Information). The color of the filtrate (Figure S6c-III, Supporting Information) becomes darker upon further increase in microwave irradiation time (45 s) of the reaction mixture. We noticed that the resultant $\mathrm{GO}$ is still highly oxidized and porous from the UV-vis spectroscopy and AFM measurement (Figure S6ab, Supporting Information), respectively, but the product yield is dramatically decreased to $\approx 50 \mathrm{wt} \%$, in comparison to $120 \mathrm{wt} \%$ product yield of $\mathrm{HGO}$ with $40 \mathrm{~s}$ of microwave irradiation. The yellow colored filtrates are fluorescent and the fluorescent intensity increases with the microwave time as shown in Figure S6d (Supporting Information). In contrast, by excluding the $\mathrm{KMnO}_{4}$ in reaction mixture, a similar dark yellow filtrate was also obtained within $30 \mathrm{~s}$ of microwave irradiation (Figure S6c-IV, Supporting Information), suggesting that $\mathrm{KMnO}_{4}$ plays an important role in slowing down the carbon gasification/etching processes. ${ }^{[44]}$ The large amount of carbon lost in the form of small organic compounds and/or gasification to $\mathrm{CO}_{2} / \mathrm{CO}$ is related to the molecular mechanisms of graphite oxidation. ${ }^{[4]}$

For an efficient approach to fabricate graphene sheets with controlled structures from graphite particles, the first requirement is to access the internal surfaces of graphite particles by an oxidant. However, due to the strong interaction and close distance between the sheets, only the edges of graphite particles and the exposed graphene surface are readily accessible; the rest of the graphene is physically blocked from interaction with the oxidant molecules. ${ }^{\text {[48] }}$ The oxidation of each layer of graphene includes several steps: First, oxidation is initiated to create oxygen containing groups, such as $-\mathrm{OH}$ and/or epoxy groups, on the basal plane and edges of graphene sheets. Further oxidation includes two simultaneous and competing processes: (i) continuing initiation of oxidation in the intrinsic graphene domains resulting in generation of more - $\mathrm{OH}$ and/or epoxy groups, referred as defect generation; and/or (ii) further oxidation of the already oxidized carbon atoms, ultimately leading to gasification of the carbon atoms (mostly $\mathrm{CO}$ or $\mathrm{CO}_{2}$ ) and generation of small organic carbon species (which are separated during filtration), resulting in vacancies and holes throughout the graphene basal planes. This process is also called defect consumption or etching. ${ }^{[20,49]}$ Continuing etching eventually leads to fracture/cutting of graphene sheets to small pieces. The relative reaction rates of these processes determine the overall speed of the graphene fabrication as well as the oxidation level, the lateral size, and holey structures of the fabricated graphene sheets.

The exact mechanism of hole generation in the graphene oxide is not fully understood, which is worthy to further study. Based on our results, additional control experiments (see the Supporting Information for more detail) and combined with previous experimental and theoretical studies, ${ }^{[45,49-54]}$ we hypothesize the following scenario might have occurred: It is known that $\mathrm{KMnO}_{4}$ preferably oxidizes existing defects, ${ }^{[45]}$ while nitronium ions have the power to oxidize both existing defects and intact graphene domains. ${ }^{[4,50,51]}$ It is very likely that the nitronium ions efficiently intercalate to the inner sites of graphite particles and initiate oxidation of graphene sheets and generates defects (functional groups such as $-\mathrm{OH}$ and epoxy groups) across the entire sheets. In the following steps, if $\mathrm{KMnO}_{4}$ was not included, these defects were quickly etched away by losing small organic molecules and/or releasing $\mathrm{CO}_{2} /$ $\mathrm{CO}$ gases. As a result, holes are generated on the graphene sheets. However, this etching step is so fast that the generated holey graphene were rapidly and uncontrollably fractured to small pieces. ${ }^{[4]}$ With $\mathrm{KMnO}_{4}$ in the reaction system, $\mathrm{MnO}_{4}^{-}$may bind to some of the epoxy/hydroxyl groups (defects), generated in the first step of oxidation by the nitronium ions, protects them from further oxidation and slows down the defect consumption/etching step. On the other hand, $\mathrm{KMnO}_{4}$ starts its own unzipping like oxidative cutting mechanism. ${ }^{[45]}$ At short microwave time $(30 \mathrm{~s})$, highly oxidized nonporous GO sheets were generated with straight edges and few holes/pores in their basal plane, similar to those fabricated with Hummers or modified Hummers methods. However with further slightly increasing the microwave time to $40 \mathrm{~s}$, the temperature was significantly increased (see Figure S1c, Supporting Information). Noted that the temperature was measured outsites of the reaction vessel, the true temperature inside should be much higher than the measured ones. At the largely increased temperatures, the $\mathrm{KMnO}_{4}$ could not protect the defects efficiently 

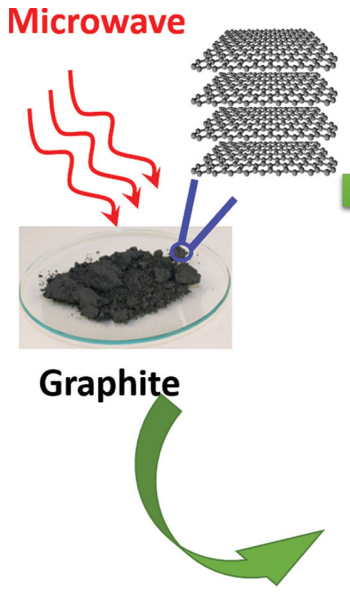
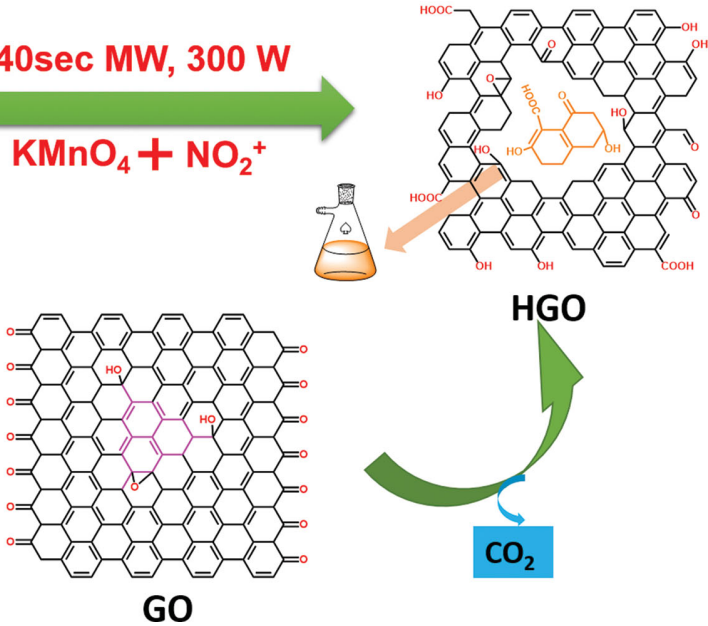

Scheme 1. Schematic drawing of proposed mechanism of HGO synthesis.

shows that the peaks at $\approx 3400 \mathrm{~cm}^{-1}(\mathrm{O}-\mathrm{H}$ stretching), $1735 \mathrm{~cm}^{-1}$ ( $\mathrm{C}=\mathrm{O}$ stretching), $1625 \mathrm{~cm}^{-1}$ (adsorbed water bending), and $1048 \mathrm{~cm}^{-1}$ (C-O stretching vibrations), were initially present in the spectrum of $\mathrm{GO}$ and $\mathrm{HGO}$, disappeared in N-rGO-10 and N-HrGO-10. This result soundly demonstrates the removal of oxygen containing functional groups from GO sheets and the GO sheets were reduced during the microwave reaction with $\mathrm{NH}_{4} \mathrm{OH}$. Meanwhile a new strong band near 1200-1240 $\mathrm{cm}^{-1}$ appears in N-rGO-10 and $\mathrm{N}-\mathrm{HrGO}-10$, which can be identified and assigned to $\mathrm{C}-\mathrm{N}$ stretching vibrations, indicating $\mathrm{N}$ was successfully incorporated into the carbon matrix of the GO sheets. Furthermore, the successful N-doping is also proved by the appearance of strong N1s along with $\mathrm{C} 1 \mathrm{~s}$ and O1s peak in the XPS survey spectrum (Figure S3a, Sup-

anymore, so etching occurs both in the basal plane and at the edges of GO, resulting in holey GO with irregular edges as shown in Scheme 1.

Heteroatom doping of graphene, especially N-doping, can effectively tailor and fine tune its electronic structures, thus has great impacts on is applications in electronics, energy storage and metal free catalysts. ${ }^{[24,28-31]}$ There are quiet a few strategies have been reported for $\mathrm{N}$-doping of graphene, however all of them require high temperature $\left(500-1000{ }^{\circ} \mathrm{C}\right)$ and/or long reaction time for N-doping (Table S4, Supporting Information). Recently, Tang et al. exploited microwave heating to reach high temperature and to shorten the doping time. ${ }^{[55]}$ However, due to the low microwave absorption capability of GO, the microwave assisted N-doping could be achieved only for pre-pyrolytic graphene oxide dry powder, which obtained by preheating of $\mathrm{GO}$ at $\approx 250^{\circ} \mathrm{C}$ before microwave treatment. Furthermore, the product is not easy for solution processible applications. Here in, again by taking an advantage of microwave heating, we report that solution processible $\mathrm{N}$ doped and concurrently reduced GO is achieved at low temperatures and with short reaction time. Specifically, a mixture of $\mathrm{GO}$ sheets and concentrated $\mathrm{NH}_{4} \mathrm{OH}$ is heated in a closed glass vessel via microwave irradiation. In $\approx 40 \mathrm{~s}$, the apparent temperature reaches to $120{ }^{\circ} \mathrm{C}$ possibly due to dielectric and/or ionic heating mechanism. With a closed looped configuration of the microwave heating system, we held this temperature for $10 \mathrm{~min}$. From UV-vis spectroscopy, FT-IR, and XPS characterization, we found that this process results in simultaneous $\mathrm{N}$-doping and reduction of $\mathrm{GO} / \mathrm{HGO}$. We refer the N-doped holey reduced GO as N-HrGO-10 and $\mathrm{N}$-doped nonporous reduced GO as N-rGO-10, 10 denotes 10 min of microwave reaction time for $\mathrm{N}$-doping.

Figure 1c and Figure S1b (Supporting Information) show that the UV absorption peak of N-HrGO-10 and N-rGO-10 red shifted to $\approx 260 \mathrm{~nm}$ along with enhanced NIR absorption, indicating the aromatic conjugation of graphene was partially restored. The FT-IR spectrum analysis of GO, HGO, N-rGO10, and N-HrGO-10 (Figure S8, Supporting Information) also porting Information) of N-rGO-10 and N-HrGO-10. Detailed quantitative study of the C1s and O1s peak (Table S1, Supporting Information) shows an increased $\mathrm{C}: \mathrm{O}$ atomic ratio and a decreased relative O1s peak intensity in $\mathrm{N}-\mathrm{rGO}-10$ and $\mathrm{N}-\mathrm{HrGO}-10$ compared to that of $\mathrm{GO}$ and $\mathrm{HGO}$, suggesting that the oxygen functional groups are extensively removed after the microwave reaction of $\mathrm{GO}$ with $\mathrm{NH}_{4} \mathrm{OH}$, consistent with the FTIR results (Figure S8, Supporting Information). It was reported that $\mathrm{NH}_{4} \mathrm{OH}$ can either serve as an epoxide ring opening agent and/or as a Lewis/Bronsted acid which reacts with epoxy/carboxyl groups of the GO, resulting in the introduction of $\mathrm{N}$ into graphitic structure along with the reduction of graphene oxide. ${ }^{[43]}$ Indeed, the $-\mathrm{OH} /$ epoxy and $-\mathrm{COOH}$ peak intensity in the C1s spectra of N-rGO-10 (Figure S2b, Supporting Information) and N-HrGO-10 (Figure 2b) are greatly decreased as compared to GO and HGO (Table S5, Supporting Information). However, the relative ratio of $\mathrm{C}=\mathrm{O}$ remained unaltered, showing that carbonyl moiety is not reactive in this reaction. Raman spectroscopy was also used to characterize the $\mathrm{HGO}$ sheets before and after N-doping. As expected, the Raman spectra (Figure S9, Supporting Information) of all the samples show D band $\left(\approx 1315 \mathrm{~cm}^{-1}\right)$ and $\mathrm{G}$ band $\left(\approx 1590 \mathrm{~cm}^{-1}\right)$ and the ratio intensities $\left(I_{\mathrm{D}} / I_{\mathrm{G}}\right)$ of $\mathrm{D}$ and $\mathrm{G}$ band does not changed upon simultaneous $\mathrm{N}$-doping and reduction. These results are consistent with previous reports that incorporation of heterogeneous $\mathrm{N}$-dopants breads the hexagonal symmetry of the graphene. ${ }^{[56]}$ Therefore even the GO was reduced during $N$-doping, the $I_{\mathrm{D}} / I_{\mathrm{G}}$ ratio would not decrease, which is in contrast to the scenario of reduction of GO to rGO without introducing any heterogeneous dopants. The surface area of the N-HrGO-10 and N-rGO-10 was also measured via methylene blue absorption method. We found that the surface area of N-rGO-10 dramatically decreased from 947 to $560 \mathrm{~m}^{2} \mathrm{~g}^{-1}$ after simultaneous reduction and N-doping process (Table S2, Supporting Information). In highly contract, the high surface area of N-HrGO-10 is largely maintained (1424 to $1194 \mathrm{~m}^{2} \mathrm{~g}^{-1}$ for HGO and N-HrGO-10, respectively). From the SEM (scanning electron microscopy) 


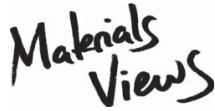

www.MaterialsViews.com
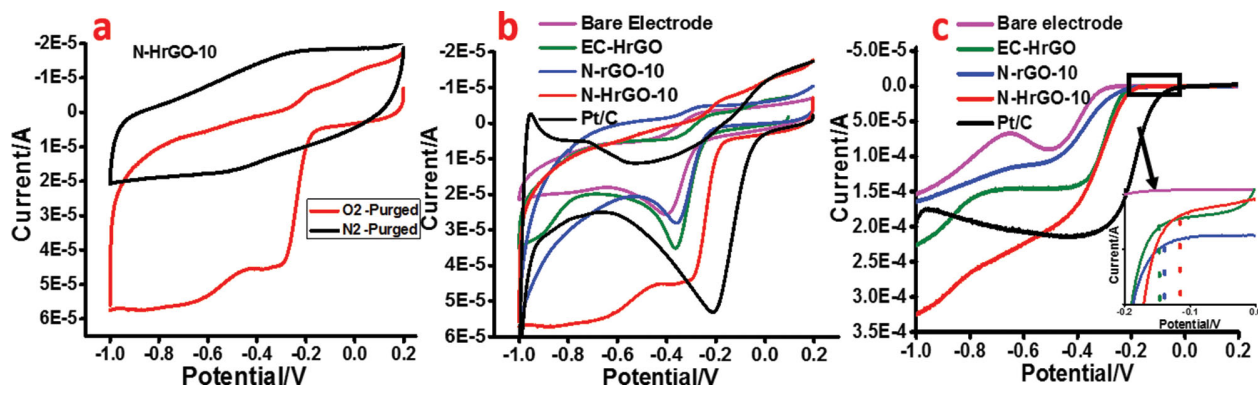

Figure 3. a) $\mathrm{CVs}$ of $\mathrm{N}-\mathrm{HrGO}-10$ in $\mathrm{N}_{2}$ and $\mathrm{O}_{2}$ saturated $0.1 \mathrm{~m} \mathrm{KOH}$ electrolyte at a scan rate of $50 \mathrm{mV} \mathrm{s}^{-1}$. b,c) CV and LSV curves of Pt/C, EC-HrGO, $\mathrm{N}-\mathrm{HrGO}-10, \mathrm{~N}-\mathrm{rGO}-10$, and bare electrode in $\mathrm{O}_{2}$ saturated $0.1 \mathrm{M} \mathrm{KOH}$ electrolyte at a scan rate of 50 and $10 \mathrm{mV} \mathrm{s}^{-1}$, respectively. Inset c) is zoomed in LSV curve of bare electrode, $\mathrm{N}-\mathrm{rGO}-10$, and $\mathrm{N}-\mathrm{HrGO}-10$. All potentials are measured using $\mathrm{Ag} / \mathrm{AgCl}$ as a reference electrode.

image of N-HrGO-10 (Figure S10, Supporting Information), we can see that its holey structure is nicely preserved during the simultaneous reduction and $\mathrm{N}$-doping process.

It is well documented that the incorporated $\mathrm{N}$ in graphene can be in different forms, which would influence the electronic structure and therefore the catalytic performance of the doped graphene. ${ }^{[34,57,58]}$ For example, pyridinic and pyrrolic $\mathrm{N}$ refers to $\mathrm{N}$ atoms bonded to two carbon atoms and donates one and two $p$-electron to the aromatic pi $(\pi)$ system, respectively. Quaternary $\mathrm{N}$ atoms are incorporated into the graphene via substituting some carbon atoms within the graphene plane. The pyridinic $\mathrm{N}$ and pyrrolic $\mathrm{N}$ are always located at the graphitic edge, whereas quaternary $\mathrm{N}$ can be both "edge-N" and "bulk-like-N". To evaluate the type and level of $\mathrm{N}$-doping by this microwave approach, we deconvoluted high resolution XPS N1s peak and summarize the relative ratio of each type of $\mathrm{N}$ species. The relative ratios of pyridinic $\mathrm{N}(398.5 \mathrm{eV})$, amine $\mathrm{N}(399.6 \mathrm{eV})$, pyrrolic $\mathrm{N}$ $(400.7 \mathrm{eV})$, quaternary $\mathrm{N}(402.0 \mathrm{eV})$, and $\mathrm{N}$-oxides (like $\mathrm{NO}$ at $403.4 \mathrm{eV}, \mathrm{NO}_{2}$ at $405.2 \mathrm{eV}$, and $\mathrm{NO}_{3}$ at $406.6 \mathrm{eV}$ ) are listed in Table S6 (Supporting Information). From this careful analysis, we found that the microwave approach results in similar $\mathrm{N}$-types as traditional heating approaches, ${ }^{[24,59]}$ even though the total $\mathrm{N}$ content is slightly higher ( 8.5 atomic\%). In addition, the relative ratio of each $\mathrm{N}$-type varies depending on the initial GO structures. With $\mathrm{HGO}$, more pyridinic $\mathrm{N}$ and pyrrolic $\mathrm{N}$ were generated in comparison to the nonporous $\mathrm{GO}$, possibly due to the difference in the amount of edges (Table S6, Supporting Information).

$\mathrm{N}$-doped carbon nanomaterials exhibited good catalytic activity for a wide range of catalytic reactions. ${ }^{[6,31,35,60,61]}$ Their performance depends on the level and type of $\mathrm{N}$-doping for the specific catalytic reaction of interest. ${ }^{[60,61]}$ It has been already reported that $\mathrm{N}$-doped graphene/CNT shows better electrocatalytic activity for ORR, ${ }^{[6,62]}$ however the detailed electrocatalytic mechanisms of these $\mathrm{N}$-doped carbon materials remains unclear. Several research groups have reported that enhanced ORR activity of N-doped carbon nanomaterials is due to the presence of pyridinic $\mathrm{N}$ at the edges ${ }^{[63,64]}$ or a combined effect from pyrrolic and pyridinic $\mathrm{N}$, which introduces an asymmetric spin density and atomic charge density in the graphene plane, making it possible for high ORR catalytic activity. ${ }^{[65]}$

The electrocatalytic activity of $\mathrm{N}$ doped holey $\mathrm{rGO}$ (N-HrGO-10) was evaluated for ORR by cyclic voltammetry
$(\mathrm{CV})$ in a $0.1 \mathrm{~m} \mathrm{KOH}$ solution saturated with oxygen and nitrogen (Figure 3a). A large reduction peak was observed in the $\mathrm{O}_{2}$ saturated electrolyte solution, but not in the $\mathrm{N}_{2}$ saturated solution, suggesting that $\mathrm{O}_{2}$ is electrocatalytically reduced on the N-HrGO-10 modified electrode. We compared the ORR capability of $\mathrm{N}-\mathrm{HrGO}-10$ with bare GC electrode, commercial Pt/C, N-rGO-10, and electrochemically reduced holey GO (EC-HrGO), which is obtained by electrochemical reduction of HGO. ${ }^{[66]}$ From their $\mathrm{CV}$ and linear sweep voltammetry (LSV) curves obtained in $\mathrm{O}_{2}$ saturated $0.1 \mathrm{~m} \mathrm{KOH} \mathrm{(Figure} \mathrm{3b,c} \mathrm{and} \mathrm{Table} \mathrm{1),} \mathrm{we} \mathrm{can} \mathrm{see} \mathrm{that}$ the N-HrGO-10 shows much better ORR catalytic activity than the bare electrode, EC-HrGO, and N-rGO-10 demonstrated by its more positive onset potential, peak potential, and higher current density, which is similar or slight better than previously reported $\mathrm{N}$-doped graphene, synthesized by traditional high temperature approaches. ${ }^{[6,57,67,68]}$ However, $\mathrm{N}-\mathrm{HrGO}-10$ still shows slightly more negative potential and lower current density at lower potential region compared to the commercial $\mathrm{Pt} / \mathrm{C}$, indicates that the $\mathrm{Pt} / \mathrm{C}$ catalyst still shows the best ORR performance. While it is noticed that at higher potentials $(>-0.6 \mathrm{~V}), \mathrm{N}-\mathrm{HrGO}-10$ shows higher current density, which indicates that it is possibly more kinetically facile toward ORR than the $\mathrm{Pt} / \mathrm{C}$ at high overpotentials.

To understand the mechanism of oxygen adsorption on the N-HrGO-10, we drew Tafel plots (Figure S11, Supporting Information) of N-HrGO-10 derived by the masstransport correction of corresponding RDE data from Figure 3c. The same data treatment was also performed for $\mathrm{Pt} / \mathrm{C}, \mathrm{N}-\mathrm{rGO}-10, \mathrm{EC}-\mathrm{HrGO}$, and bare electrode for comparison. The Tafel slopes from the plots were summarized in Table 1 . The commercial $\mathrm{Pt} / \mathrm{C}$ electrocatalyst shows two different Tafel slopes (75.22 and $121.10 \mathrm{mV}$ per decade at lower and higher current density region, respectively), which indicates a Langmuir adsorption and Temkin adsorption of oxygen. ${ }^{[56]}$ Similar to $\mathrm{Pt} / \mathrm{C}$, the Tafel plots of N-HrGO-10 also shows two slopes (Table 1) but they are much lower from that of the $\mathrm{Pt} / \mathrm{C}$ catalysts, indicates a possible different oxygen adsorption mechanism. Moreover, the N-HrGO-10 and EC-HrGO shows smaller Tafel slopes than the N-rGO-10, demonstrating that the existence of nanoholes and/or the large surface area could improve the catalytic activities of carbon-based catalysts. Furthermore, we 
Table 1. Electrochemical parameters (onset potential, peak potential, current density at $-0.4 \mathrm{~V}$ and Tafel slopes-b1 and -b2 calculated at low and high current density region, respectively) of different catalysts for ORR estimated from CV and RDE polarization curves in $0.1 \mathrm{~m} \mathrm{KOH}$ solution. All potential are measured using $\mathrm{Ag} / \mathrm{AgCl}$ as a reference electrode.

\begin{tabular}{|c|c|c|c|c|c|}
\hline \multirow[t]{2}{*}{ Catalyst } & \multirow[t]{2}{*}{$\begin{array}{c}\text { Onset potential } \\
{[\mathrm{V}]}\end{array}$} & \multirow[t]{2}{*}{$\begin{array}{c}\text { Peak potential } \\
{[\mathrm{V}]}\end{array}$} & \multirow[t]{2}{*}{$\begin{array}{l}\text { Current density } \\
{\left[\mathrm{mA} \mathrm{cm}^{2}\right] \text { at }-0.4 \mathrm{~V}}\end{array}$} & \multicolumn{2}{|c|}{$\begin{array}{c}\text { Tafel slope } \\
\text { [mV/decade] }\end{array}$} \\
\hline & & & & b1 & b2 \\
\hline Bare electrode & -0.18 & -0.40 & 0.74 & 57.28 & 143.93 \\
\hline EC-HrGO & -0.15 & -0.36 & 2.08 & 58.58 & 107.11 \\
\hline $\mathrm{N}-\mathrm{rGO}-10$ & -0.14 & -0.36 & 1.04 & 87.46 & 152.57 \\
\hline $\mathrm{N}-\mathrm{HrGO}-10$ & -0.11 & -0.28 & 2.41 & 58.37 & 104.78 \\
\hline $\mathrm{Pt} / \mathrm{C}$ & -0.02 & -0.21 & 3.05 & 75.22 & 121.10 \\
\hline
\end{tabular}

also found that ORR activity of $\mathrm{N}-\mathrm{HrGO}$ depends on the microwave reaction time of $\mathrm{HGO}$ with $\mathrm{NH}_{4} \mathrm{OH}$. At longer reaction time, the relative ratios of $\mathrm{N}$-types (Table $\mathrm{S} 6$, Supporting Information) were changed, which largely influenced their ORR catalytic activity. From the CV curves (Figure S12, Supporting Information), the onset potential and peak potential were negatively shifted and the kinetic current decreased on $\mathrm{N}-\mathrm{HrGO}-30$, which is obtained via $30 \mathrm{~min}$ of microwave reaction time. Among all the graphene modified electrodes, N-HrGO-10 modified electrodes exhibits the lowest onset potential and peak potential, and highest ORR current.

ORR can occur either via a direct four electron reduction pathway or a two electron pathway. In the four electron pathway, oxygen is directly reduced to water, while in the two electron pathway, oxygen is reduced to peroxide. In fuel cell, the direct four electron pathway is preferred to achieve better energy conversion efficiency and prevent corrosion of cell components due to the hazardous peroxides. LSV of EC-HrGO (Figure 3c) clearly shows a two-step reaction pathways for ORR $(-0.2$ to $-0.4 \mathrm{~V}$ and -0.7 to $-1.0 \mathrm{~V})$, which indicates the two-electron pathway mechanism while LSV of $\mathrm{N}-\mathrm{HrGO}-10$ shows almost one-step reaction pathway, indicates four-electron pathway for ORR.

To carefully quantify the electron transfer numbers and the formation of peroxide species $\left(\mathrm{HO}_{2}{ }^{-}\right)$during the ORR process, we performed rotating ring disk electrode (RRDE) measurements. The $\% \mathrm{HO}_{2}{ }^{-}$and the electron transfer number were determined by the following equations:

$$
\begin{aligned}
& \% \mathrm{HO}_{2}^{-}=\frac{\left(200 \times \frac{I_{\mathrm{r}}}{\mathrm{N}}\right)}{\left(I_{\mathrm{d}} \times \frac{I_{\mathrm{r}}}{\mathrm{N}}\right)} \\
& n=\frac{\left(4 \times I_{\mathrm{d}}\right)}{\left(I_{\mathrm{d}}+\frac{I_{\mathrm{r}}}{\mathrm{N}}\right)}
\end{aligned}
$$

where $I_{\mathrm{d}}$ and $I_{\mathrm{r}}$ is the current measured from the disc and ring electrode, respectively, and $\mathrm{N}$ is current collection efficiency of the Pt ring electrode. $\mathrm{N}$ was determined to be 0.424 from the redox reaction of $\mathrm{K}_{3} \mathrm{Fe}(\mathrm{CN})_{6}$. Figure $4 \mathrm{a}$ shows the disk and ring currents from N-HrGO-10, N-HrGO-30, ECHrGO, N-rGO-10, and Pt/C modified electrodes, respectively. Notably, the N-HrGO-10 and Pt/C modified electrodes exhibited the lowest ring current among these graphene modified electrodes. The ring current increased on the N-HrGO-30 and EC-HrGO modified electrode shows the highest ring current. Based on the ring and disk currents, the electron transfer numbers $(n)$ and $\% \mathrm{HO}_{2}^{-}$were calculated (Figure $4 \mathrm{~b}, \mathrm{c}$ ). The EC-HrGO modified electrode demonstrated the lowest electron transfer number of 2.5-2.6, and it also generates the highest percentage of peroxide $(75 \%)$. The electron transfer number for the N-HrGO-30 and N-rGO-10 are similar, slightly increased to about 3 and the amount of peroxide generated decreased to $45 \%-70 \%$ depending on the potentials applied during the ORR. In sharp contrast, the $n=3.5$ to 3.8 for the N-HrGO-10 modified electrode over the whole

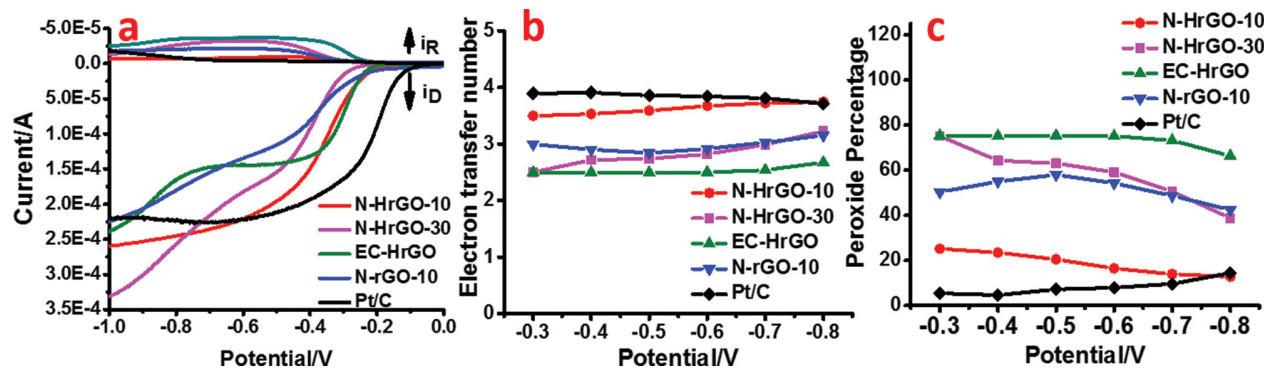

Figure 4. a) RRDE voltammogram of N-HrGO-10, N-HrGO-30, EC-HrGO, N-rGO-10, and Pt/C modified electrode in oxygen saturated $0.1 \mathrm{~m} \mathrm{KOH}$ at a scan rate of $10 \mathrm{mV} \mathrm{s}^{-1}$ and $1600 \mathrm{rpm}$ rotation speed. b,c) The number of electron transfer and relative peroxide \%, respectively, for all catalyst calculated from RRDE voltammogram. All potentials are measured using $\mathrm{Ag} / \mathrm{AgCl}$ as a reference electrode. 
potential range, emphasizing that the ORR proceeds mainly via a direct four-electron pathway. In consistent to the electron transfer number, the \% of peroxide is as low as $12 \%$. The much better performance of N-HrGO-10 over N-rGO-10 is possibly due to its relatively high concentration of pyridinic and pyrrolic $\mathrm{N}$ and the existence of holes and edges, which also provide higher surface area, largely facilitate the mass transport of $\mathrm{O}_{2}$ and the electrolyte. On the other hand, EC-HrGO should have the same or similar amount edges, holes, and surface area compared to the N-HrGO-10, its poor performance is very likely due to the lack of $\mathrm{N}$ doped catalytic centers. Moreover, N-HrGO-30 also shows lower electron transfer number and higher $\% \mathrm{HO}_{2}^{-}$, possibly due to the change in N-type upon prolonged microwave irradiation time. From XPS N1s peak analysis of N-HrGO-10 and N-HrGO-30 (Figure 2c,d), we summarized N-type and relative ratio in Tables S1 and S6 (Supporting Information). Even though the atomic N\% is not dramatically changed at different microwave reaction time, but the pyridinic $\mathrm{N}$, pyrrolic $\mathrm{N}$ is decreased at longer microwave time (30 min), which can be the possible reason for decreased ORR catalysis.

To further study how the hole structures on the N-HrGO-10 influence their electron transfer kinetics involved in ORR, rotating disc electrode (RDE) measurements (Figure S13, Supporting Information) were performed in $\mathrm{O}_{2}$ saturated $0.1 \mathrm{~m} \mathrm{KOH}$ solutions under various electrode rotating rates. The same study also performed on the N-rGO-10 and $\mathrm{Pt} / \mathrm{C}$ for comparison. As shown in Figure S13 (Supporting Information), the current density is increased with rotation speed from 250 to $2500 \mathrm{rpm}$ due to the enhanced diffusion of the electrolytes and $\mathrm{O}_{2}$. The kinetic parameters, such as kinetic current density $\left(J_{\mathrm{K}}\right)$, and the effective diffusion coefficient of $\mathrm{O}_{2}\left(D_{0}\right)$ in ORR is then analyzed using the Koutecky-Levich (K-L) equation. ${ }^{[69]}$

$1 / J=1 / J_{L}+1 / J_{K}=1 / B \omega^{0.5}+1 / J_{K}$

where $B=0.62 \mathrm{nF} C_{0}\left(D_{0}\right)^{2 / 3} \mathrm{v}^{-1 / 6}$ and $J_{K}=n F k C_{0}$.

Here, $J$ is the measured current density, $J_{L}$ and $J_{K}$ are the diffusion limiting and kinetic limiting current densities, $\omega$ is the angular rotation rate of the disc electrode ( $\mathrm{rad} / \mathrm{s}), B$ is Levich constant, $n$ is the number of electrons transferred in the oxygen reduction reaction $\left(\mathrm{mol}^{-1}\right), F$ is the Faraday constant $\left(F=96485 \mathrm{C} \mathrm{mol}^{-1}\right), D_{0}$ is the effective diffusion coefficient of $\mathrm{O}_{2}\left(\mathrm{~cm}^{2} \mathrm{~s}^{-1}\right), v$ is the kinematic viscosity of the electrolyte $\left(\mathrm{cm}^{2} \mathrm{~s}^{-1}\right), C_{0}$ is the oxygen concentration $\left.(\mathrm{mol} \mathrm{cm})^{-3}\right)$, and $k$ is the electron transfer rate constant.

We plotted the $\mathrm{K}-\mathrm{L}$ plot $\left(J^{-1}\right.$ vs $\left.\omega^{-1 / 2}\right)$ for N-HrGO10, N-rGO-10, and $\mathrm{Pt} / \mathrm{C}$ at various electrode potentials (Figure 5a,b and Figure S13d, Supporting Information). From the linearity and parallelism of the plot at various electrode potentials, we consider that the ORR is a typical first order reaction kinetics with respect to the dissolved oxygen concentration. The slope and intercept of the $\mathrm{K}-\mathrm{L}$ plot gives the Levich constant $(B)$ and $J_{K}$, which then are used to calculate the effective diffusion coefficient constant of $\mathrm{O}_{2}\left(D_{0}\right)$ and electrochemical rate constant $k$, respectively, by using
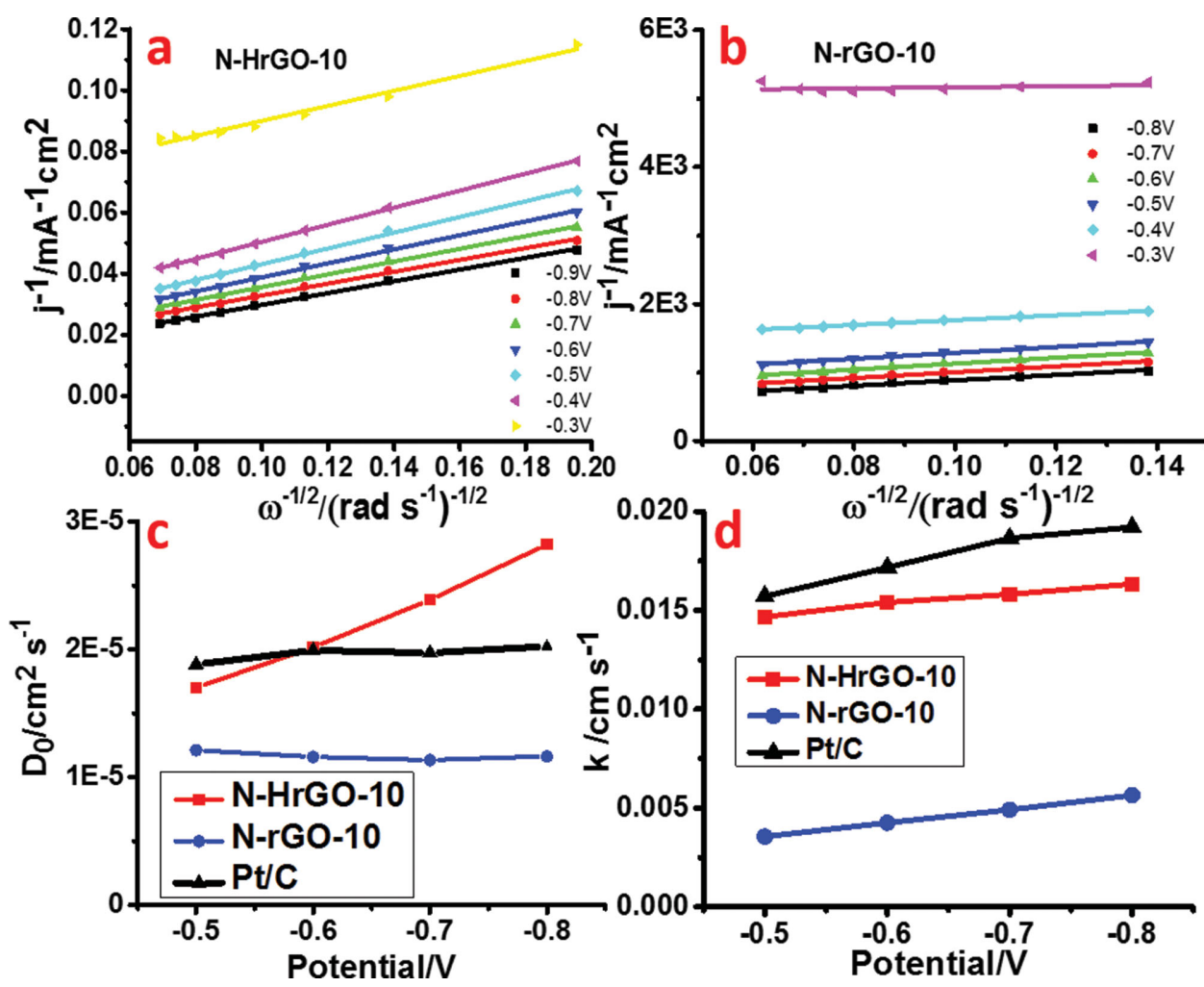

Figure 5. a,b) $\mathrm{K}-\mathrm{L}$ plot of N-HrGO-10 and N-rGO-10, obtained based on the LSV curves at different rotating speeds (Figure S13, Supporting Information), respectively. c) Calculated oxygen diffusion coefficient and d calculated rate constant for ORR, using slope and intercept from $\mathrm{K}-\mathrm{L}$ plot of $\mathrm{N}-\mathrm{HrGO}-10, \mathrm{~N}-\mathrm{rGO}-10$, and $\mathrm{Pt} / \mathrm{C}$. All potentials are measured using $\mathrm{Ag} / \mathrm{AgCl}$ as a reference electrode. 


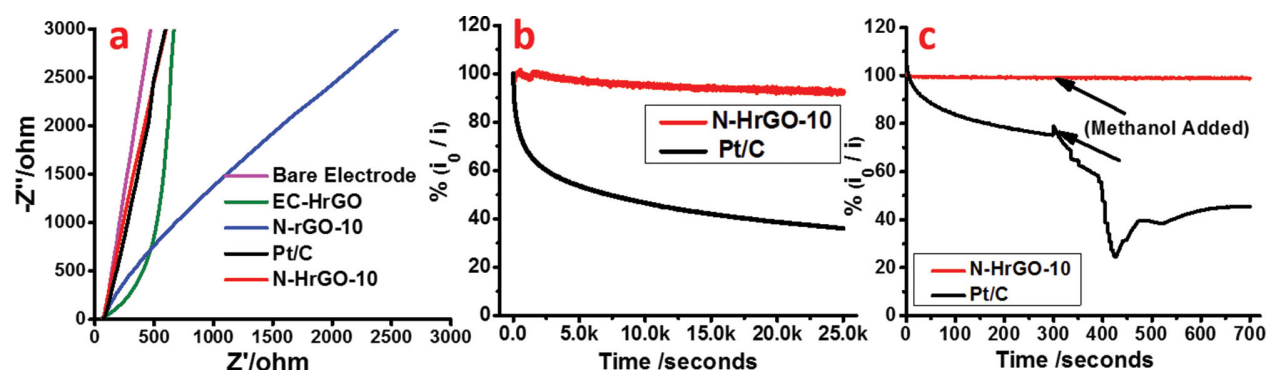

Figure 6. a) Nyquist plot of EIS for the oxygen reduction on the bare electrode, EC-HrGO, N-rGO-10, N-HrGO-10, and Pt/C. b) Durability testing of the $\mathrm{Pt} / \mathrm{C}$ and $\mathrm{N}-\mathrm{HrGO}-10$ electrode for $\approx 7 \mathrm{~h}$ at $-0.38 \mathrm{~V}$ and $1000 \mathrm{rpm}$ speed. c) Chronoamperometric response of the $\mathrm{N}-\mathrm{HrGO}-10 \mathrm{and} \mathrm{Pt} / \mathrm{C}$ modified electrode for ORR upon addition of methanol after about $\approx 300 \mathrm{~s}$ at $-0.38 \mathrm{~V}$. All potentials are measured using $\mathrm{Ag} / \mathrm{AgCl}$ as a reference electrode.

electron transfer number $\mathrm{n}$ calculated from RRDE measurement. From Figure 5d, the N-HrGO-10 has more than 4 times higher $k$ than the N-rGO-10. Here, for the first time, we found that the effective diffusion coefficient of $\mathrm{O}_{2}$ is also much higher (Figure 5c) in N-HrGO-10, which quantitatively demonstrates that the holey structures on the basal plane of graphene indeed contributed to the enhanced diffusion of oxygen. The calculated kinetic current density $\left(J_{k}\right)$ and rate constant $(k)$ from Equation (3) for $\mathrm{N}-\mathrm{HrGO}-10$ is found to be $462.38 \mathrm{~mA} \mathrm{~cm} \mathrm{~m}^{-2}$ and $0.015 \mathrm{~cm} \mathrm{~s}^{-1}$, respectively, which is much higher than other reported values for heteroatom doped graphene catalyst. ${ }^{[70,71]}$ The relatively higher kinetic and diffusion current density, along with the $4 \mathrm{e}^{-}$pathway of the N-HrGO-10 demonstrates its great potential to replace the commercial $\mathrm{Pt} / \mathrm{C}$ catalyst for ORR.

Electrochemical impedance spectroscopy (EIS) studies were performed for N-HrGO-10, N-rGO-10, EC-HrGO, and $\mathrm{Pt} / \mathrm{C}$ modified electrodes, respectively, to understand the underlying physics associated with their electroreduction catalytic activity. It is reported that the high frequency part in an EIS (Figure 6a), is attributed to the interfacial resistance at the surface of the active electrode, middle frequency part corresponds to the charge transfer resistance, and the low frequency part is related to the impedance from the diffusion of electrolyte and $\mathrm{O}_{2}$ through the catalysts. ${ }^{[43]}$ The fitting of the EIS using a modified randles equivalent circuit shows that $\mathrm{N}-\mathrm{HrGO}-10$ has a similar charge transfer resistance, interfacial resistance, and oxygen/electrolyte diffusion resistance to the $\mathrm{Pt} / \mathrm{C}$ electrodes. The nonporous $\mathrm{N}-\mathrm{rGO}-10$ shows much higher diffusion resistance, further demonstrating that the hole structures of graphene promotes better oxygen diffusion to the surface of electrode so that the redox reaction can be performed more efficiently. Based on these results we can conclude that the porous structure and $\mathrm{N}$-doping in N-HrGO-10 attribute for better electrocatalytic activity toward ORR.

For practical applications, the catalyst must have good catalytic activity along with good stability and durability. The durability of $\mathrm{N}-\mathrm{HrGO}-10$ with respect to commercial $\mathrm{Pt} / \mathrm{C}$ was assessed through chronoamperometric measurements at $-0.38 \mathrm{~V}(\mathrm{vs} \mathrm{Ag} / \mathrm{AgCl})$ in an $\mathrm{O}_{2}$ saturated $0.1 \mathrm{~m} \mathrm{KOH}$ at a rotation rate of $1600 \mathrm{rpm}$. From the Figure $6 \mathrm{~b}$ we can see that, while more than $50 \%$ of the original activity of the $\mathrm{Pt} / \mathrm{C}$ is lost within $4 \mathrm{~h}$, the $\mathrm{N}-\mathrm{HrGO}-10$ loses only $\approx 7 \%$ of its original activity after $7 \mathrm{~h}$, demonstrating that the N-HrGO-10 have far better durability. We also performed methanol cross over test to check stability of $\mathrm{N}-\mathrm{HrGO}-10$ and $\mathrm{Pt} / \mathrm{C}$ against methanol. From Figure 6c, we can see that $\mathrm{Pt} / \mathrm{C}$ loses its $\approx 35 \%$ of its original activity in the presence of methanol due to blockage of the active sites on Pt nanoparticle by methanol adsorption, ${ }^{[72]}$ while the introduction of methanol does not affect the ORR activity of N-HrGO-10, shows better stability against methanol cross over effect and great potential to replace $\mathrm{Pt} / \mathrm{C}$ as a metal free catalysts.

\section{Conclusion}

In summary, by replacing traditional heating to microwave irradiation, holey graphene oxide sheets or graphene oxide sheets without holes can be controllably, directly, and rapidly (tens of seconds) fabricated from graphite powder via a one-step-one-pot reaction with a production yield of $120 \mathrm{wt} \%$ of graphite. Again by taking advantage of the unique heating mechanism of microwave irradiation, a fast and low temperature approach to fabricate solution processible $\mathrm{N}$ doped graphene is developed. The N-doped holey graphene sheets (N-HrGO-10) demonstrated remarkable electro-catalytic capabilities for the electrochemical ORR. The existence of the nanoholes not only provides a "short cut" for efficient mass transport, but also creates more catalytic centers due to the increased surface area and edges associated with the nanoholes. For the first time, we experimentally measure the effective diffusion constant of $\mathrm{O}_{2}$ for $\mathrm{N}-\mathrm{HrGO}-10$ and $\mathrm{N}-\mathrm{rGO}-10$, which quantitatively demonstrates that the hole structures on the basal plane of graphene indeed contributed to the enhanced diffusion of oxygen in N-HrGO-10. Although the onset potential of $\mathrm{N}-\mathrm{HrGO}-10$ for ORR is slight negative in comparison to that of commercial $\mathrm{Pt} / \mathrm{C}$ catalysts, the $\mathrm{N}-\mathrm{HrGO}-10$ shows much better stability and durability against methanol poisoning. The capability for rapid fabrication and $\mathrm{N}$-doping of holey GO can lead us to develop efficient catalysts which can replace precious coin metals for energy generation and storage, such as fuel cells and metal-air batteries.

\section{Experimental Section}

Synthesis of GO and HGO: Graphite powder (20 mg, SigmaAldrich, $\leq 20 \mu \mathrm{m}$ lateral size) was mixed with concentrated sulfuric acid ( $8 \mathrm{~mL}, 98 \%$, ACS grade) in a round bottom flask. The mixture 

small

www.MaterialsViews.com

is then swirled and cooled in an ice bath for approximately 5 min. Then concentrated nitric acid ( $2 \mathrm{~mL}, 70 \%$, ACS grade) was added and again cooled in ice bath for approximately $5 \mathrm{~min}$. After that $\mathrm{KMnO}_{4}$ (100 mg, ACS grade) was added to the ice cooled acid mixture. The entire mixture was swirled and mixed for another $30 \mathrm{~s}$ and placed into a microwave reactor chamber (CEM DiscoverSP). The reaction mixture was subjected to microwave irradiation $(300 \mathrm{~W})$ for different time to produce GO and HGO. $30 \mathrm{~s}$ of microwave results in GO, while $40 \mathrm{~s}$ of microwave results in $\mathrm{HGO}$. Subsequently, after microwave irradiation, the mixture is transferred to $200 \mathrm{~mL}$ of ice containing $5 \mathrm{~mL}$ of $35 \% \mathrm{H}_{2} \mathrm{O}_{2}$ to quench the reaction and then filtered through polycarbonate filter paper $(0.2 \mu \mathrm{m}$ pore size) follow by washing with diluted hydrochloric acid $(\approx 4 \%)$ and deionized (DI) water. A colloidal graphene oxide (HGO and GO) solution is obtained by mild bath sonication $(\approx 30 \mathrm{~min})$. The dispersion obtained is then left undisturbed for seven days to let the unexfoliated graphite particles precipitate out. The supernatant was carefully decanted and this solution is stable for months in water without significant precipitation.

$N$ Doping of GO and HGO: $\mathrm{HGO}$ or $\mathrm{GO}\left(3 \mathrm{~mL}, 0.55 \mathrm{mg} \mathrm{mL}^{-1}\right)$ was mixed with concentrated ammonium hydroxide ( $3 \mathrm{~mL}, 29.2 \%$, ACS plus grade) in pyrex tube and sealed with Teflon cap. This mixture is heated in microwave at $120^{\circ} \mathrm{C}$ for different time $(5,10,15$, $30 \mathrm{~min}$ ) with the pressure limit set to 15 bars, which resulted into nitrogen doping and simultaneously reduction of $\mathrm{GO}$ and $\mathrm{HGO}$ to form N-rGO-x and N-HrGO-x, respectively, where $x$ denotes microwave reaction time. After the reaction, the mixture is cooled down to $50{ }^{\circ} \mathrm{C}$ and neutralized with sulfuric acid in order to precipitate out the product and then dialyzed with $12 \mathrm{kD}$ membrane dialysis tube with DI water to remove any salt residues. Finally, the product was centrifuged and bath-sonicated to redisperse in water to achieve desired concentration.

Material Characterization: The morphology of the graphene samples were studied by using Tapping mode AFM NanoscopeIlla Multimode scanning probe microscope system (Digital Instruments, Bruker) with a J scanner and STEM/SEM (Hitachi S-4800). The sample for AFM and SEM was prepared by simple drop casting of sample on freshly cleaved mica surface and $\mathrm{Cu}$ tape, respectively, and allowed it for air dry. The sample for STEM was also prepared by drop casting a sample $(2 \mu \mathrm{L})$ on carbon supported Cu grid (400 meshes, type or company) and allowed it to dry in air. X-ray photoelectron spectroscopy (XPS) characterization was performed after depositing a layer of all kinds of catalysts onto a gold film (a $100 \mathrm{~nm}$ gold layer was sputter-coated on silicon with a $10 \mathrm{~nm} \mathrm{Ti}$ adhesion layer). The thickness of the film on the gold substrates was roughly $30-50 \mathrm{~nm}$. XPS spectra were acquired using a Thermo Scientific K-Alpha system with a monochromatic Al $\mathrm{K} \alpha \mathrm{x}$-ray source $(\mathrm{h} v=1486.7 \mathrm{eV})$. For data analysis, Shirley background subtraction was performed, and the spectra were fit with Gaussian/Lorentzian peaks using a minimum deviation curvefitting method (part of the Avantage software package). The surface composition of each species was determined by the integrated peak areas and the Scofield sensitivity factor provided by the Avantage software. Absorption spectra were recorded on a Cary 5000 UV-vis-NIR spectrophotometer in the double beam mode using a $1 \mathrm{~cm}$ quartz cuvette. Raman spectra of the samples (deposited on anodisc membrane) were collected using Raman Microscope (Confocal) - Wi-Tec, Alpha 300-M+ with an excitation laser at $785 \mathrm{~nm}$. FT-IR spectra of the samples (deposited on $\mathrm{CaF}_{2}$ windows) were acquired with a Perkin Elmer Spotlight 300 system using the transmission mode. The surface area of GO, HGO, N-rGO10 , and $\mathrm{N}-\mathrm{HrGO}-10$ is measured by methylene blue (MB) adsoption method and descried in detail in the Supporting Information.

Electrochemical Measurements: All the ORR experiments were conducted by using a computer-controlled potentiostat $(\mathrm{CHI} 760 \mathrm{C}$, $\mathrm{CH}$ Instrument, USA) with a typical three-electrode cell. A platinum wire and saturated $\mathrm{Ag} / \mathrm{AgCl}$ electrode is used as the counter-electrode and the reference electrode, respectively, in all measurement. A glassy carbon electrode was used as a working electrode and was polished each time prior to use with alumina slurry. All of the catalysts $(\approx 2 \mathrm{mg})$ were dispersed in $25 \%$ ethanol $(1 \mathrm{~mL})$ containing nafion ( 0.5 wt\%) by bath sonication. Then $2 \mu \mathrm{L}$ of this dispersion was loaded on glassy carbon electrode and allowed to dry in vacuum. Before each testing, the electrolyte $(0.1 \mathrm{~m} \mathrm{KOH})$ was saturated with oxygen $\left(\mathrm{O}_{2}\right)$ by bubbling $\mathrm{O}_{2}$ for $30 \mathrm{~min}$. Cyclic voltammogram experiments were typically performed at the scan rate of $50 \mathrm{mV} \mathrm{s}^{-1}$ in $\mathrm{O}_{2}$ saturated $0.1 \mathrm{M} \mathrm{KOH}$. For control experiments in (nitrogen) $\mathrm{N}_{2}$ saturated $\mathrm{KOH}, \mathrm{N}_{2}$ was bubbled in $0.1 \mathrm{~m} \mathrm{KOH}$ for $30 \mathrm{~min}$, while other conditions remain unchanged. RDE experiments were performed using glassy carbon disc electrode $(3 \mathrm{~mm}$ diameter) in $\mathrm{O}_{2}$ saturated $0.1 \mathrm{M} \mathrm{KOH}$ with different rotation speed varying from 250 to $2500 \mathrm{rpm}$ and $10 \mathrm{mV} \mathrm{s}^{-1}$ scan rate. For a comparison, the commercially available Johnson Matthey (JM) Pt/C 40 wt\% (Johnson Matthey Corp., Pt loading: 40 wt\% Pt on carbon) electrode was also prepared similarly to other catalyst as above mentioned. For the RRDE measurement, catalyst and electrodes are prepared by the same method as RDE measurement, except using RRDE electrode (GC disc and Pt ring electrode). The chronoamperometry experiment was conducted by measuring current for $25000 \mathrm{~s}$ at $-0.38 \mathrm{~V}$ potential and at $1000 \mathrm{rpm}$ rotation speed with continues maintaining oxygen flow to avoid any oxygen concentration effect. For methanol cross over effect, we conducted another amperometric experiment for $700 \mathrm{~s}$ with same experiment condition as above, except $2 \mathrm{~mL}$ of methanol was added at $300 \mathrm{~s}$ during the experiment. The electrochemical impedance spectra (ESI) for ORR on the catalyst electrodes are measured in $\mathrm{O}_{2}$-saturated $0.1 \mathrm{M}$ $\mathrm{KOH}$ solution at $-0.31 \mathrm{~V}$ versus $\mathrm{Ag} / \mathrm{AgCl}$.

\section{Supporting Information}

Supporting Information is available from the Wiley Online Library or from the author.

\section{Acknowledgements}

This material is based upon work supported by the National Science Foundation under Grant Nos. STTR 1346496 and CBET 1438493.

[1] H. S. Chen, T. N. Cong, W. Yang, C. Q. Tan, Y. L. Li, Y. L. Ding, Prog. Nat. Sci. 2009, 19, 291.

[2] S. Chu, A. Majumdar, Nature 2012, 488, 294.

[3] D. Linden, Handbook of Batteries and Fuel Cells, McGraw Hill Higher Education, New York 1984. 
[4] D. S. Yu, E. Nagelli, F. Du, L. M. Dai, J. Phys. Chem. Lett. 2010, 1, 2165.

[5] R. L. Liu, D. Q. Wu, X. L. Feng, K. Mullen, Angew. Chem., Int. Ed. 2010, 49, 2565.

[6] L. T. Qu, Y. Liu, J. B. Baek, L. M. Dai, ACS Nano 2010, 4, 1321.

[7] K. P. Gong, F. Du, Z. H. Xia, M. Durstock, L. M. Dai, Science 2009, $323,760$.

[8] R. I. Jafri, N. Rajalakshmi, S. Ramaprabhu, J. Power Sources 2010, $195,8080$.

[9] T. C. Nagaiah, S. Kundu, M. Bron, M. Muhler, W. Schuhmann, Electrochem. Commun. 2010, 12, 338.

[10] R. K. Joshi, P. Carbone, F. C. Wang, V. G. Kravets, Y. Su, I. V. Grigorieva, H. A. Wu, A. K. Geim, R. R. Nair, Science 2014, 343, 752.

[11] J. Bai, X. Zhong, S. Jiang, Y. Huang, X. Duan, Nat. Nanotechnol. 2010, 5, 190.

[12] P. Kuhn, A. Forget, D. Su, A. Thomas, M. Antonietti, J. Am. Chem. Soc. 2008, 130, 13333.

[13] M. Bieri, M. Treier, J. Cai, K. Ait-Mansour, P. Ruffieux, O. Groning, P. Groning, M. Kastler, R. Rieger, X. Feng, K. Mullen, R. Fasel, Chem. Commun. 2009, 45, 6919.

[14] O. Akhavan, ACS Nano 2010, 4, 4174.

[15] M. D. Fischbein, M. Drndic, Appl. Phys. Lett. 2008, 93, 113107.

[16] Y. Zhu, S. Murali, M. D. Stoller, K. J. Ganesh, W. Cai, P. J. Ferreira, A. Pirkle, R. M. Wallace, K. A. Cychosz, M. Thommes, D. Su, E. A. Stach, R. S. Ruoff, Science 2011, 332, 1537.

[17] S. Wang, F. Tristan, D. Minami, T. Fujimori, R. Cruz-Silva, M. Terrones, K. Takeuchi, K. Teshima, F. Rodríguez-Reinoso, M. Endo, Carbon 2014, 76, 220.

[18] X. Zhao, C. M. Hayner, M. C. Kung, H. H. Kung, ACS Nano 2011, 5, 8739.

[19] X. Wang, L. Jiao, K. Sheng, C. Li, L. Dai, G. Shi, Sci. Rep. 2013, 3, 1996.

[20] T. H. Han, Y. K. Huang, A. T. Tan, V. P. Dravid, J. Huang, J. Am. Chem. Soc. 2011, 133, 15264.

[21] Y. Zhao, C. Hu, L. Song, L. Wang, G. Shi, L. Dai, L. Qu, Energy Environ. Sci. 2014, 7, 1913.

[22] Y. Lin, K. A. Watson, J.-W. Kim, D. W. Baggett, D. C. Working, J. W. Connell, Nanoscale 2013, 5, 7814.

[23] D. Zhou, Y. Cui, P.-W. Xiao, M.-Y. Jiang, B.-H. Han, Nat. Commun. 2014, 5, 4716.

[24] X. Li, H. Wang, J. T. Robinson, H. Sanchez, G. Diankov, H. Dai, J. Am. Chem. Soc. 2009, 131, 15939.

[25] Y. Xue, D. Yu, L. Dai, R. Wang, D. Li, A. Roy, F. Lu, H. Chen, Y. Liu, J. Qu, Phys. Chem. Chem. Phys. 2013, 15, 12220.

[26] C. Zhang, N. Mahmood, H. Yin, F. Liu, Y. Hou, Adv. Mater. 2013, $25,4932$.

[27] H. Wang, Y. Zhou, D. Wu, L. Liao, S. Zhao, H. Peng, Z. Liu, Small 2013, 9, 1316.

[28] H. B. Wang, M. S. Xie, L. Thia, A. Fisher, X. Wang, J. Phys. Chem. Lett. 2014, 5, 119.

[29] H. B. Wang, T. Maiyalagan, X. Wang, ACS Catal. 2012, 2, 781.

[30] T. Hu, X. Sun, H. Sun, G. Xin, D. Shao, C. Liu, J. Lian, Phys. Chem. Chem. Phys. 2014, 16, 1060.

[31] D. W. Chang, E. K. Lee, E. Y. Park, H. Yu, H. J. Choi, I. Y. Jeon, G. J. Sohn, D. Shin, N. Park, J. H. Oh, L. Dai, J. B. Baek, J. Am. Chem. Soc. 2013, 135, 8981.

[32] Y. Y. Shao, S. Zhang, M. H. Engelhard, G. S. Li, G. C. Shao, Y. Wang, J. Liu, I. A. Aksay, Y. H. Lin, J. Mater. Chem. 2010, 20, 7491.

[33] Z. Yang, Z. Yao, G. Li, G. Fang, H. Nie, Z. Liu, X. Zhou, X. a. Chen, S. Huang, ACS Nano 2011, 6, 205.

[34] B. Zhang, Z. Wen, S. Ci, S. Mao, J. Chen, Z. He, ACS Appl. Mater. Interfaces 2014, 6, 7464.

[35] L. Chen, R. Du, J. Zhu, Y. Mao, C. Xue, N. Zhang, Y. Hou, J. Zhang, T. Yi, Small, DOI 10.1002/smll.201402472.

[36] Z. S. Wu, W. C. Ren, L. Xu, F. Li, H. M. Cheng, ACS Nano 2011, 5, 5463.

[37] L. Panchakarla, K. Subrahmanyam, S. Saha, A. Govindaraj, H. Krishnamurthy, U. Waghmare, C. Rao, Adv. Mater. 2009, 21, 4726.

[38] A. L. Reddy, A. Srivastava, S. R. Gowda, H. Gullapalli, M. Dubey, P. M. Ajayan, ACS Nano 2010, 4, 6337.
[39] D. H. Deng, X. L. Pan, L. A. Yu, Y. Cui, Y. P. Jiang, J. Qi, W. X. Li, Q. A. Fu, X. C. Ma, Q. K. Xue, G. Q. Sun, X. H. Bao, Chem. Mater. 2011, 23, 1188.

[40] X. R. Wang, X. L. Li, L. Zhang, Y. Yoon, P. K. Weber, H. L. Wang, J. Guo, H. J. Dai, Science 2009, 324, 768.

[41] H. L. Guo, P. Su, X. F. Kang, S. K. Ning, J. Mater. Chem. A 2013, 1, 2248.

[42] Z. H. Sheng, L. Shao, J. J. Chen, W. J. Bao, F. B. Wang, X. H. Xia, ACS Nano 2011, 5, 4350.

[43] Z. Q. Jiang, Z. J. Jiang, X. N. Tian, W. H. Chen, J. Mater. Chem. A 2014, 2, 441.

[44] M. A. Patel, H. Yang, P. L. Chiu, D. D. Mastrogiovanni, C. R. Flach, K. Savaram, L. Gomez, A. Hemnarine, R. Mendelsohn, E. Garfunkel, H. Jiang, H. He, ACS Nano 2013, 7, 8147.

[45] D. V. Kosynkin, A. L. Higginbotham, A. Sinitskii, J. R. Lomeda, A. Dimiev, B. K. Price, J. M. Tour, Nature 2009, 458, 872.

[46] S. H. Aboutalebi, R. Jalili, D. Esrafilzadeh, M. Salari, Z. Gholamvand, S. Aminorroaya Yamini, K. Konstantinov, R. L. Shepherd, J. Chen, S. E. Moulton, ACS Nano 2014, 8, 2456.

[47] A. Bagri, C. Mattevi, M. Acik, Y. J. Chabal, M. Chhowalla, V. B. Shenoy, Nat. Chem. 2010, 2, 581.

[48] A. M. Dimiev, J. M. Tour, ACS Nano 2014, 8, 3060.

[49] K. J. Ziegler, Z. Gu, H. Peng, E. L. Flor, R. H. Hauge, R. E. Smalley, J. Am. Chem. Soc. 2005, 127, 1541.

[50] J. Liu, A. G. Rinzler, H. J. Dai, J. H. Hafner, R. K. Bradley, P. J. Boul, A. Lu, T. Iverson, K. Shelimov, C. B. Huffman, F. Rodriguez-Macias, Y. S. Shon, T. R. Lee, D. T. Colbert, R. E. Smalley, Science 1998, $280,1253$.

[51] Z. Y. Chen, K. Kobashi, U. Rauwald, R. Booker, H. Fan, W. F. Hwang, J. M. Tour, J. Am. Chem. Soc. 2006, 128, 10568.

[52] J.-L. Li, K. N. Kudin, M. J. McAllister, R. K. Prud'homme, I. A. Aksay, R. Car, Phys. Rev. Lett. 2006, 96, 176101.

[53] T. Sun, S. Fabris, Nano Lett. 2012, 12, 17.

[54] Z. Y. Li, W. H. Zhang, Y. Luo, J. L. Yang, J. G. Hou, J. Am. Chem. Soc. 2009, 131, 6320

[55] P. Tang, G. Hu, Y. Gao, W. Li, S. Yao, Z. Liu, D. Ma, Sci. Rep. 2014 4, 5901.

[56] Y. Zhang, K. Fugane, T. Mori, L. Niu, J. Ye, J. Mater. Chem. 2012, 22, 6575.

[57] L. F. Lai, J. R. Potts, D. Zhan, L. Wang, C. K. Poh, C. H. Tang, H. Gong, Z. X. Shen, L. Y. Jianyi, R. S. Ruoff, Energy Environ. Sci. 2012, 5, 7936.

[58] Y. Jiao, Y. Zheng, M. Jaroniec, S. Z. Qiao, J. Am. Chem. Soc. 2014 136, 4394.

[59] Y. Sun, C. Li, G. Shi, J. Mater. Chem. 2012, 22, 12810.

[60] X.-K. Kong, C. L. Chen, Q. W. Chen, Chem. Soc. Rev. 2014, 43, 2841.

[61] S. Navalon, A. Dhakshinamoorthy, M. Alvaro, H. Garcia, Chem. Rev. 2014, 114, 6179.

[62] K. Gong, F. Du, Z. Xia, M. Durstock, L. Dai, Science 2009, 323, 760

[63] K. A. Kurak, A. B. Anderson, J. Phys. Chem. C 2009, 113, 6730.

[64] C. V. Rao, C. R. Cabrera, Y. Ishikawa, J. Phys. Chem. Lett. 2010, 1, 2622.

[65] L. P. Zhang, Z. H. Xia, J. Phys. Chem. C 2011, 115, 11170.

[66] X. Y. Peng, X. X. Liu, D. Diamond, K. T. Lau, Carbon 2011, 49, 3488.

[67] S. Y. Wang, D. S. Yu, L. M. Dai, D. W. Chang, J. B. Baek, ACS Nano 2011, 5, 6202.

[68] Z. Lin, G. Waller, Y. Liu, M. Liu, C. P. Wong, Adv. Energy Mater. 2012, 2, 884.

[69] R. Liu, D. Wu, X. Feng, K. Mullen, Angew. Chem. 2010, 49, 2565.

[70] K. Moses, V. Kiran, S. Sampath, C. N. Rao, Chem. Asian J. 2014, 9 , 838.

[71] Y. Zheng, Y. Jiao, L. Ge, M. Jaroniec, S. Z. Qiao, Angew. Chem. 2013, 52, 3110.

[72] Y. Zhang, Q. H. Huang, Z. Q. Zou, J. F. Yang, W. Vogel, H. Yang, J. Phys. Chem. C 2010, 114, 6860

Received: November 14, 2014 Revised: December 27, 2014 Published online: February 12, 2015 